\title{
The effect of repeated endotoxin injections on gonadotropin secretion in ewes
}

\author{
A.P. Herman ${ }^{1}$, K. Kopycińska, A. Krawczyńska, K. Romanowicz and D. Tomaszewska-Zaremba \\ The Kielanowski Institute of Animal Physiology and Nutrition, Polish Academy of Sciences, 05-110 Jabłonna, Poland
}

KEY WORDS: ewe, inflammation, LPS, $\mathrm{LH}, \mathrm{FSH}$

Received: 25 April 2014

Revised: 13 June 2014

Accepted: 21 August 014

${ }^{1}$ Corresponding author:

e-mail: andrewherman@wp.pl

\begin{abstract}
Although it is well known that acute inflammation induced by a single injection of the bacterial endotoxin, lipopolysaccharide (LPS), induces a stress response and suppresses luteinizing hormone (LH) secretion, the effects of repeated endotoxin administration on gonadotropin secretion in sheep have not been studied yet. In this work, the influence of inflammation induced by six days of intravenous LPS injection ( $400 \mathrm{ng} \cdot \mathrm{kg}^{-1}$ per day) on the release of $\mathrm{LH}$ and follicle-stimulating (FSH) hormones was evaluated. Anoestrous ewes were bled twice a day $1 \mathrm{~h}$ before and $3 \mathrm{~h}$ after LPS injection. Endotoxin injection decreased $(P<0.05)$ the release of LH from the first day of the experiment. Moreover, on day 5 , the suppression of LH secretion was sustained and could also be detected in the samples collected before the next LPS injection. In contrast, elevation $(P<0.05)$ of $\mathrm{FSH}$ release was detected starting from the second dose of the endotoxin. The increased FSH concentration persisted until the end of the experiment. Each LPS injection stimulated $(P<0.05)$ cortisol release, but from days 3 to 6 , this elevation was about three times lower than the level determined during the first two days. The obtained results show that ewes exposed to repeated administration of endotoxin lost their ability to restore proper LH release relatively quickly. This disturbance in gonadotropin secretion could, in part, be associated with the stress induced by LPS, as well as with endotoxin-induced inflammatory challenges.
\end{abstract}

\section{Introduction}

An inflammatory challenge induced by bacterial infection is considered a potent negative regulator of the reproductive process in females. It has already been reported that inflammation induced by the administration of the bacterial endotoxin, lipopolysaccharide (LPS), was able to suppress the circulating concentrations of luteinizing hormone (LH) in a number of species, including rats, sheep, cattle and non-human primates (Daniel et al., 2003), potentially leading to the disruption of ovarian cyclicity (Peter et al., 1989). It is postulated that the anti-luteinizing effects of such inflammation are focused on the suppression of gonadotropin-releasing hormone $(\mathrm{GnRH})$ secretion in the hypothalamus (Herman and Tomaszewska-Zaremba, 2010). However, the endotoxin-induced inhibition of LH secretion could also result from downregulation of $\mathrm{GnRH}$ receptor gene expression in the anterior pituitary (AP), potentially decreasing its responsiveness to $\mathrm{GnRH}$ stimulation (Herman and Tomaszewska-Zaremba, 2010). LPS seems to affect GnRH/LH secretion mostly indirectly by inducing the synthesis of pro-inflammatory cytokines, such as interleukin (IL)-1 $\beta$, IL-6 and tumour necrosis factor (TNF) $\alpha$. These cytokines penetrate the hypothalamic area during inflammation and are able to alter the GnRH pulse amplitude, duration and 
frequency and to interfere with the female ovulatory cycle (Karsch et al., 2002; Herman et al., 2012). It is worth mentioning that this antigonadotropic effect of central pro-inflammatory cytokines could result not only from their direct action on GnRH secretion, but also involves other central pathways activated by these cytokines in the hypothalamic area (Tomaszewska-Zaremba et al., 2013). The inhibition of GnRH secretion may be induced by a prostaglandin (PGs)dependent pathway. The pharmacological blockade of cyclooxygenase (COX)-1 and 2, enzymes required for PGs production, prevented the cytokine-dependent suppression of $\mathrm{GnRH} / \mathrm{LH}$ secretion (Yoo et al., 1997). Inflammation can also affect reproduction via the activation of the hypothalamic-pituitary-adrenal axis (HPA). Certain components of this axis, such as arginine vasopressin, corticotropin-releasing hormone, adrenocorticotrophic hormone and glucocorticosteroids, including cortisol, are known suppressors of GnRH/LH secretion (Maeda and Tsukamura, 2006).

The objective of this work was to determine the effect of repeated inflammation induced by sixfold injection of LPS on the release of LH and follicle-stimulating hormone (FSH) in anoestrous ewes. The current paper is the first scientific report using the model of repeated endotoxin administration on gonadotropin secretion in sheep in contrast to the prolonged infusion of LPS used by Battaglia et al. (2000).

\section{Material and methods}

\section{Animals}

The studies were performed on adult, 3-year-old Polish Mountain sheep in their anoestrous season (April-May). The animals were maintained indoors in individual pens and exposed to natural daylight. The ewes were in good condition and well adapted to the experimental conditions; additionally, they always had visual contact with the neighbouring ewes to prevent stress due to social isolation. The animals were fed a consistent diet of commercial concentrates, with hay and water available ad libitum.

All of the procedures on animals were performed with the consent of the Local Ethics Committee of the Warsaw University of Life Sciences.

\section{Experimental procedures}

In ewes $(n=6)$, prolonged immunological stress was induced by intravenous (i.v.) administration of LPS from Escherichia coli 055:B5 (Sigma, St. Louis,
MO, USA) dissolved in saline $(0.9 \% \mathrm{w} / \mathrm{V} \mathrm{NaCl})$ (Baxter, Deerfield, IL, USA) at a concentration of $10 \mathrm{mg} \cdot \mathrm{1}^{-1}$ into the jugular vein $\left(400 \mathrm{ng} \cdot \mathrm{kg}^{-1}\right)$. For six days, the animals received a single injection of LPS or saline at 9 a.m. The blood samples taken to measure the hormone concentrations were obtained daily $1 \mathrm{~h}$ before and $3 \mathrm{~h}$ after the peripheral administration of saline or LPS. Blood samples were collected into heparinized tubes and immediately centrifuged for $10 \mathrm{~min}$ at $1000 \mathrm{~g}$ at $4^{\circ} \mathrm{C}$. Plasma was stored at $-80^{\circ} \mathrm{C}$ until assayed.

\section{Radioimmunoassay of plasma hormones}

Plasma LH concentrations were assayed with a double-antibody radioimmunoassay using antiovine-LH and anti-rabbit- $\gamma$-globulin antisera and ovine standard (teri.oLH, Tucker Endocrine Research Institute), according to Stupnicki and Madej (1976). The assay sensitivity was $0.3 \mathrm{ng} \cdot \mathrm{ml}^{-1}$, and the intra- and inter-assay coefficients of variation were $8 \%$ and $11.5 \%$, respectively.

The concentration of FSH was determined by double antibody radioimmunoassay (RIA) using anti-ovine-FSH (teri.anti-oFSH) and anti-rabbit$\gamma$-globulin antisera, according to L'Hermite et al. (1972). The anti-FSH as well as the FSH standard (teri. oFSH-and teri. FSH ig),was kindly supplied by Dr. L.E. Reichert Jr. (Tucker Endocrine Research Institute LLC, Atlanta, Georgia, USA). The assay sensitivity was $1.5 \mathrm{ng} \cdot \mathrm{ml}^{-1}$, and the intra- and inter-assay coefficients of variation were $3.5 \%$ and $11.0 \%$, respectively.

The cortisol concentrations were determined by radioimmunoassay according to Kokot and Stupnicki (1985) using rabbit anti-cortisol antisera (R/75) and an HPLC-grade cortisol standard (SIGMA, USA). The assay sensitivity was $1 \mathrm{ng} \cdot \mathrm{ml}^{-1}$, and the intra- and interassay coefficients of variation for cortisol were $9 \%$ and $12 \%$, respectively.

\section{Statistical data analysis}

The results are presented as the means $\pm \mathrm{SEM}$. To identify the treatment effects, Wilcoxon's nonparametrical test for paired samples was used. To determine the time-dependent effect of repeated endotoxin treatment on hormone secretion, all of the values were compared with the first measurement taken before the first LPS administration. To identify the effect of particular LPS injections, the values obtained before and after each treatment were compared. Statistical significance was defined as $P<0.05$. 


\section{Results}

Each injection of endotoxin suppressed $(P<0.05)$ LH secretion compared with the basal level assayed before the first LPS administration $\left(4.5 \mathrm{ng} \cdot \mathrm{ml}^{-1} \pm\right.$ 0.2 ; Figure $1 \mathrm{~A})$. Moreover, starting from the $5^{\text {th }}$ day of the experiment, the treated animals also showed reduced $(P<0.05)$ LH levels in the samples collected $1 \mathrm{~h}$ before endotoxin injection. In other words, after 4 days of LPS treatment, a 24-h period was not enough to restore LH release to the basal level.

From the second day onward, a significant $(P<0.05)$ elevation in FSH release was observed in treated animals compared with their basal levels (4.2 $\left.\mathrm{ng} \cdot \mathrm{ml}^{-1} \pm 0.3\right)$. This elevated FSH concentration persisted until the end of the experiment, although its highest level was determined on the $5^{\text {th }}$ day $\left(12.9 \mathrm{ng} \cdot \mathrm{ml}^{-1} \pm 2.4\right.$; Figure 1B).
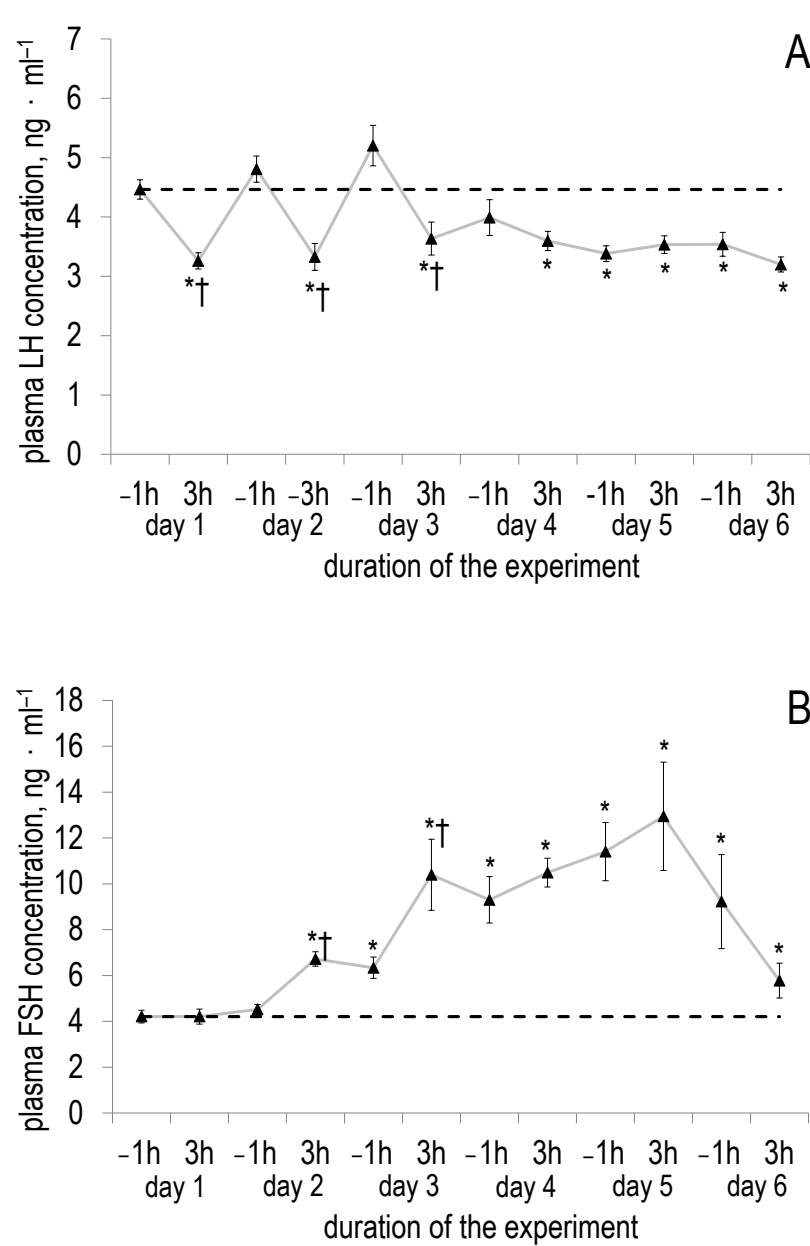

Figure 1. Effect of lipopolysaccharide (LPS) administration on luteinizing hormone (LH) (A) and follicle-stimulating hormone (FSH) (B) concentrations in the blood plasma assayed $1 \mathrm{~h}$ before and $3 \mathrm{~h}$ after each endotoxin ( $400 \mathrm{ng} \cdot \mathrm{kg}^{-1}$; i.v.) treatment. The data are presented as the mean values \pm SEM. $P<0.05$ - asterisk indicates values that differ from the first measurement taken before the first LPS injection, according to Wilcoxon's test; ${ }^{\dagger} P<0.05$ - cross indicates values that differ from the measurement taken before LPS injection during each particular day of the experiment, according to Wilcoxon's test

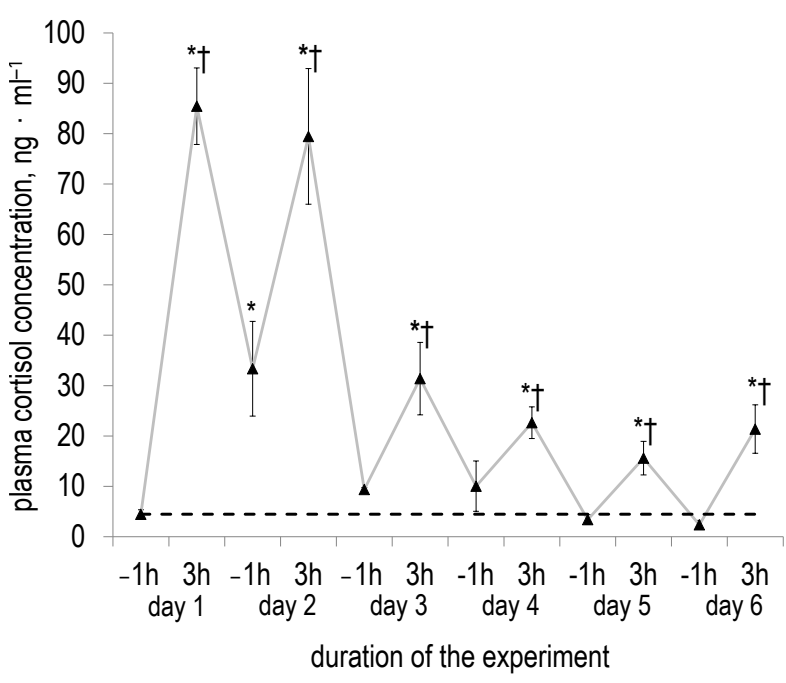

Figure 2. Effect of lipopolysaccharide (LPS) administration on cortisol concentrations in the blood plasma, as assayed $1 \mathrm{~h}$ before and $3 \mathrm{~h}$ after each endotoxin $\left(400 \mathrm{ng} \cdot \mathrm{kg}^{-1}\right.$; i.v.) treatment. The data are presented as the mean values \pm SEM. $P<0.05$ - asterisk indicates values that differ from the first measurement taken before the first LPS injection, according to Wilcoxon's test; ${ }^{\dagger} P<0.05$ - cross indicates values that differ from the measurement taken before LPS injection during each particular day of the experiment, according to Wilcoxon's test

Each injection of endotoxin stimulated $(P<0.05)$ cortisol secretion compared with the basal levels $\left(4.5 \mathrm{ng} \cdot \mathrm{ml}^{-1} \pm 0.9\right)$. From the $3^{\text {rd }}$ day onward, however, the LPS-dependent stimulation of cortisol oscillated after having caused 30\% stimulation, as determined on the $1^{\text {st }}$ day of the experiment (85.4 $\mathrm{ng} \cdot \mathrm{ml}^{-1} \pm 7.60$; Figure 2$)$.

\section{Discussion}

B The suppressive effect of endotoxin-induced inflammation on LH release in anoestrous ewes is not surprising because this was clearly demonstrated in our previous study (Herman et al., 2010). Nevertheless, the current study shows that a single $24 \mathrm{~h}$ period is sufficient to diminish the LPS-dependent suppression of LH secretion. On the other hand, the stimulatory effect of immune stress on FSH release was observed from the second injection of endotoxin. The results of our previous study performed on anoestrous ewes suggested no effect of a single endotoxin treatment on the circulating levels of FSH (Herman et al., 2010). In the same study, however, increased $F S H \beta$ transcription was detected in the AP. The current results seem to explain the observed phenomenon and suggest that the endotoxin-induced changes in FSH secretion require time for the synthesis and accumulation of this hormone in the gonadotropes. It is worth mentioning that although endotoxins generally interrupted the preovulatory 
oestradiol peak and delayed or blocked the LH/FSH surges and oestrus in cycling ewes, some individuals evinced a stimulatory effect of LPS infusion on FSH secretion (Battaglia et al., 2000). These results led us to conclude that the elevated FSH level following endotoxin administration could be a consequence of the suppression of oestradiol secretion by immune stress, leading to the temporary release of FSH secretion from negative feedback inhibition. In the anoestrous phase, oestradiol inhibits gonadotropin secretion and is suppressed by oestradiol action. Therefore, it could be speculated that the inflammatory-dependent reduction of oestradiol secretion temporarily releases FSH secretion from the control of the oestradiol negative-feedback system.

Although elevation of cortisol release was observed after each injection of endotoxin, from the $3^{\text {rd }}$ day onward the LPS-dependent stimulation of cortisol was significantly reduced. These findings, together with analysis of the LH and FSH secretion patterns, appear to show that the strongest change in gonadotropin release occurred in the later stages of the experiment, when the LPS-dependent stimulation of cortisol was relatively low. Moreover, from the $5^{\text {th }}$ day of the experiment onward, the samples collected before LPS treatment were characterized by reduced LH concentrations and 'normal' levels of cortisol. The changes in gonadotropin secretion occurring during immune challenge can be an effect of the activation of the hypothalamic-pituitaryadrenal (HPA) stress axis. Immune stress induced by endotoxin stimulates cortisol release in a variety of animal species, including sheep (Tilbrook et al., 2000; Debus et al., 2002). It is held that inflammatory-dependent HPA axis activation plays an important role in the inhibition of reproduction, especially affecting LH release (Coleman et al., 1993; Debus et al., 2002). Immune stress stimulates not only cortisol release, but also other HPA axis components, increases the synthesis and release of arginine vasopressin and corticotropin-releasing hormone in the hypothalamus, stimulates secretion of adrenocorticotrophic hormone from the pituitary and corticosterone or cortisone from the adrenal cortex (Dadoun et al., 1998; Melmed, 2001). All of them exhibit inhibitory proprieties in relation to the HPG axis (Battaglia et al., 1998; Dobson et al., 2003; Maeda and Tsukamura, 2006). Nevertheless, activation of the HPA axis does not seem to be essential for reproductive disorders during endotoxin-induced inflammatory challenges. A study carried out on sheep showed that the inhibition of 11b-hydroxylase, an enzyme necessary for cortisol biosynthesis, leading to the blockage of cortisol secretion, did not reduce the suppression of the pulsatile GnRH and LH release induced by endotoxin administration (Debus et al., 2002). It is worth mentioning that the suppressive effect of cortisol on LH release also seems to be dependent on the reproductive status of the ewes (Oakley et al., 2009). It can be speculated that the factors that play a pivotal role in the alteration of gonadotropin secretion during repeated periods of inflammation are, in fact, the pro-inflammatory cytokines. A study carried out on mice focusing on the analysis of the differences in cytokine release after single and triplicate LPS administration showed that repeated endotoxin injections significantly enhanced the circulating and brain levels of such cytokines as IL-1 $\alpha$, IL-6 and TNF $\alpha$ (Erickson and Banks, 2011).

\section{Conclusions}

In conclusion, repeated endotoxin administration leads to disordered gonadotropin secretion in anoestrous ewes in a time-dependent manner. The role of endotoxin-induced stress in the modulation of LH and FSH during repeated LPS treatment should not be underestimated. Still, from the $5^{\text {th }}$ day of experimentation onward, decreased LH concentrations and unaffected cortisol levels were observed in the samples collected before LPS injection, suggesting the pivotal role of endotoxininduced inflammatory challenges in the induction of this disorder.

\section{Acknowledgements}

This research was supported by the Project Ministry of Science and Higher Education 'Iuventus Plus’ No. IP2011 017371.

\section{References}

Battaglia D.F., Brown M.E., Krasa H.B., Thrun L.A., Viguie' C., Karsch F.J., 1998. Systemic challenge with endotoxin stimulates corticotropin-releasing hormone and arginine vasopressin secretion into hypophyseal portal blood: coincidence with gonadotropin-releasing hormone suppression. Endocrinology 139, 4175-4181

Battaglia D.F., Krasa H.B., Padmanabhan V., Viguié C., Karsch F.J., 2000. Endocrine alterations that underlie endotoxin-induced disruption of the follicular phase in ewes. Biol. Reprod. 62, 45-53

Coleman E.S., Elsasser T.H., Kemppainen R.J., Coleman D.A., Sartin J.L., 1993. Effect of endotoxin on pituitary hormone secretion in sheep. Neuroendocrinology 58, 111-122

Dadoun F., Guillaume V., Sauze N., Farisse J., Velut J.G., Orsoni J.C., Gaillard R., Oliver C., 1998. Effect of endotoxin on the hypothalamic-pituitary-adrenal axis in sheep. Eur. J. Endocrinol. 138, 193-197

Daniel J.A., Abrams M.S., de Souza L., Wagner C.G., Whitlock B.K., Sartin J.L., 2003. Endotoxin inhibition of luteinizing hormone in sheep. Domest. Anim. Endocrinol. 25, 13-19 
Debus N., Breen K.M., Barrell G.K., Billings H.J., Brown M., Young E.A., Karsch F.J., 2002. Does cortisol mediate endotoxin-induced inhibition of pulsatile luteinizing hormone and gonadotropinreleasing hormone secretion? Endocrinology 143, 3748-3758

Dobson H., Ghuman S., Prabhakar S., Smith R., 2003. A conceptual model of the influence of stress on female reproduction. Reproduction 125, 151-163

Erickson M.A., Banks W.A., 2011. Cytokine and chemokine responses in serum and brain after single and repeated injections of lipopolysaccharide: Multiplex quantification with path analysis. Brain Behav. Immun. 25, 1637-1648

Herman A.P., Misztal T., Romanowicz K., Tomaszewska-Zaremba D., 2012. Central injection of exogenous IL-1 $\beta$ in the control activities of hypothalamic-pituitary-gonadal axis in anestrous awes. Reprod. Domest. Anim. 47, 44-52

Herman A.P., Romanowicz K., Tomaszewska-Zaremba D., 2010. Effect of LPS on reproductive system at the level of the pituitary of anestrous ewes. Reprod. Domest. Anim. 45, e351-e359

Herman A.P., Tomaszewska-Zaremba D., 2010. Effect of endotoxin on the expression of $\mathrm{GnRH}$ and GnRHR genes in the hypothalamus and anterior pituitary gland of anestrous ewes. Anim. Reprod. Sci. 120, 105-111

Karsch F.J., Battaglia D.F., Breen K.M., Debus N., Harris T.G., 2002. Mechanisms for ovarian cycle disruption by immune/ inflammatory stress. Stress 5, 101-112

Kokot F., Stupnicki R., 1985. Radioimmunoassay and Competitive Radioimmunoassay Methods Used in the Clinic (in Polish). $2^{\text {nd }}$ Edition. PZWL, Warsaw
L'Hermite M., Niswender G.D., Reichert L.E., Midgley A.R., 1972. Serum follicle stimulating hormone in sheep as measured by radioimmunoassay. Biol. Reprod. 6, 325-332

Maeda K., Tsukamura H., 2006. The impact of stress on reproduction: are glucocorticoids inhibitory or protective to gonadotropin secretion? Endocrinology 147, 1085-1086

Melmed S., 2001. The immuno-neuroendocrine interface. J. Clin. Invest. 108, 1563-1566

Oakley A.E., Breen K.M., Clarke I.J., Karsch F.J., Wagenmaker E.R., Tilbrook A.J., 2009. Cortisol reduces gonadotropin-releasing hormone pulse frequency in follicular phase ewes: influence of ovarian steroids. Endocrinology 150, 341-349

Peter A.T., Bosu W.T.K., De Decher R.J., 1989. Suppression of preovulatory luteinizing hormone surges in heifers after intrauterine infusions of Escherichia coli endotoxin. Amer. J. Vet. Res. 50, 368-373

Stupnicki R., Madej A., 1976. Radioimmunoassay of LH in blood plasma of farm animals. Endokrynologie 68, 6-13

Tilbrook A.J., Turner A.I., Clarke I.J., 2000. Effects of stress on reproduction in non-rodent mammals: the role of glucocorticoids and sex differences. Rev. Reprod. 5, 105-113

Tomaszewska-Zaremba D., Herman A.P., Misztal T., 2013. Does central IL-1 $\beta$ affect $\mathrm{GnRH}$ secretion in the hypothalamus of anoestrous ewes via different regulatory pathways? J. Anim. Feed Sci. 22, 5-12

Yoo M.J., Nishihara M., Takahashi M., 1997. Involvement of prostaglandins in suppression of gonadotropin-releasing hormone pulse generator activity by tumor necrosis factor-a. J. Reprod. Dev. 43, 181-187 